\title{
Associations between shyness and maternal and paternal bonds across adolescence
}

\begin{abstract}
Objective: The aim of this study was to examine the relationship between shyness and the parental bond in early $(\mathrm{N}=227)$ and late adolescence $(\mathrm{N}=248)$ through participants' perceptions of their bond with their parents.

Method: Shy subjects were compared with their non-shy peers across three dimensions of their perception of parenting behavior: (a) care, (b) encouragement towards autonomy, and (c) overprotection. Participants completed a parental bond measure and a measure of shyness.

Results:Results showed that shy adolescents perceived their parents as less warm and supportive, less encouraging of autonomy and independence, and more overprotective than non-shy youth did. No significant differences were found in relation to gender and age.

Conclusion: Results indicate that the perceived quality of the parent-adolescent relationship is higher in non-shy than in shy subjects since the latter perceived their parents to be more intrusive and protective than non-shy participants did. These results are consistent with previous findings on the influence of parental behaviour on shy children and extend these results by confirming that adolescents report a similar tendency in their parents' behavior.
\end{abstract}

Keywords: shyness, adolescence, maternal bond, paternal bond
Volume 7 Issue 5 - 2017

Ponti Lucia,Tani Franca

Department of Health Sciences, University of Florence, Italy

Correspondence: Lucia Ponti,Via di San Salvi, 12 - 50135 Florence, Italy, Tel 39055 2755079, Email pontilucia@gmail.com

Received: November 25, 2016 | Published: March 24, 2017

\section{Introduction}

The family, and particularly the parent-child relationship, provides one of the most important social contexts for child development. Several studies have shown that a good quality parent-child relationship can affect children's well-being, ${ }^{-1,2}$ while a poor quality of this relationship is associated with various forms of psychopathology. ${ }^{3}$

Previous research has also indicated that parenting can significantly influence the development and maintenance of shyness in children. In particular, shyness in infancy has been found to be associated with a particular type of parenting. That is, the parents of shy children are overprotective, tend to control their children's lives and to discourage their independence and autonomy. ${ }^{4}$ The experience of such parental behaviors tends to promote and reinforce children's shyness. ${ }^{5}$ For example, Coplan and colleagues have found that shy children whose mothers were intrusive and controlling towards them were more likely to demonstrate internalizing problems and social dissatisfaction than shy children whose mothers were less overprotective. At the same time, they also have found that the relationship between shyness and psychological and social difficulties was significantly less evident for shy children whose mothers were more warm and supportive. ${ }^{6}$

Although the importance of the parental relationship on the psychological and social development of shy children during childhood has been sufficiently analyzed, there has been a paucity of research on shy adolescents. Nevertheless, during this period, important biological, cognitive, and social changes occur, and although peers become increasingly influential during adolescence, parenting behaviours continue to assume an influential role on adolescent adjustment. ${ }^{7}$ Therefore, the main purpose of this study is to give a contribution to literature on parenting by examining its influence on shy adolescents.

\section{A conceptualization of shyness}

Shyness has been defined as a tendency to feel anxious and to show inhibited behavior in interpersonal situations, ${ }^{8}$ for instance, to be afraid or experience discomfort upon meeting people. In particular, certain situations, such as interacting with authority figures, members of the opposite sex and strangers, are more likely to elicit shyness. Studies have also consistently found that shy people appear to be at risk for later maladjustment, such as psychological and social difficulties. ${ }^{9,10}$

In particular, shyness has been considered to be a risk factor for the development of internalizing problems, including low self-esteem, ${ }^{11}$ excessive self-consciousness, ${ }^{12}$ fear of negative evaluation, and loneliness. ${ }^{13}$ Moreover shy people have been found to be more likely than non-shy people to develop various forms of emotional disorders, such as depression and anxiety, ${ }^{14-16}$

Shyness is also associated with several types of interpersonal difficulties, such as expressing one's own opinions or talking in the presence of others, meeting people, and establishing and maintaining satisfying relationships. ${ }^{17,18}$ Shy people, in comparison to people who are not shy, have fewer social relationships, and these are less intimate and supportive. ${ }^{11,17}$ As a result, they receive less social support from their social networks than their non-shy counterparts. Moreover, both in childhood and in adolescence, shyness is associated with peer rejection, exclusion, and victimization. ${ }^{19}$

\section{The child-parent bond}

Studies on child-parent relations have identified some basic dimensions that are related to specific aspects of child adjustment. In particular, researchers have recognized two key dimensions of parenting, namely parental care and parental control. The concept of parental care refers to a parenting style characterized by affection, 
emotional warmth, empathy and closeness; and it is opposed to a parenting style typified by aloofness, indifference and neglect. The other dimension, parental control, includes excessive psychological control and intrusiveness over the child. ${ }^{20}$ The construct of parental control involves encouragement of children's dependence on parents, and it refers to parental behaviors that limit child autonomy and freedom, and that prevent the development of their independence. ${ }^{21}$

Extensive research has repeatedly shown a relationship between these dimensions of parenting and child adjustment, demonstrating that lack of adequate parental care is a crucial risk factor for child development. Specifically, both low levels of parental care and high levels of parental control were found to be associated with psychiatric symptoms in adolescence, such as depression and phobic anxiety ${ }^{22}$ and with a wide range of mental disorders in adulthood. ${ }^{23}$ On the other hand, high levels of parental care were negatively correlated with mental disorders in children, such as anxiety, depression, somatic complaints, and social maladjustment,$^{24}$ and positively correlated with positive self-image. ${ }^{25}$ Moreover, researchers have found that parental warmth is related to lower levels of externalizing and internalizing problems, ${ }^{26}$ that higher parental support and care are associated with psychological well-being, academic competence, and higher selfesteem in children and adolescents, ${ }^{7}$ and those parents' supportive behaviors appear to promote the quality of adolescents' friendships. ${ }^{27}$ On the other hand, higher psychological control was found to be linked with internalizing problems, such as depression and anxiety. ${ }^{28,29}$ Overall, research has consistently supported the notion that parenting behaviors are associated with child psychological and social adjustment.

\section{The influence of child age and gender on parenting}

Even if the parental bond remains quite stable over time, the nature of the parent-child relationship changes with child age. In particular, during adolescence this relationship changes from being asymmetrical, which is typical from early to late childhood, to being symmetrical. ${ }^{30}$ Some studies have shown that the most important dimension that changes during child development is parental control. ${ }^{25}$ During adolescence, youths perceive their parents as more encouraging of autonomy and less psychologically controlling, but they also perceive their parental bond as less affectionate and strong. ${ }^{31}$ Other researchers have found those adolescents' feelings of support and cohesion that they experience from parent relationships decline during the transition from pre- to mid- and late-adolescence. ${ }^{32,33}$ Nevertheless, van Well and colleagues have indicated that the perceived quality of the parental bond becomes less positive in the transition from early to mid-adolescence but improves in late adolescence. ${ }^{34}$

Despite the growing body of research on the parent-child relationship, research data are rather inconsistent with respect to child gender differences. Arim \& Shapka ${ }^{28}$ reported that there were no significant differences in parental behavior between girls and boys. Nevertheless, other authors have found that child gender may affect parental education style. For example, Bonaiuto and colleagues found that girls perceived more protection from their father than did boys, ${ }^{35}$ while Pierro and colleagues found that girls reported higher parental control and overprotection from both parents than did boys. ${ }^{25}$ Finally, others authors have reported that girls perceived higher levels of care both from their mothers and from their fathers, and also perceived greater control from their father than did boys. ${ }^{24}$

\section{Shyness and parenting}

Given that parenting behavior plays an important role in the promotion of a child's well being, the literature on shyness has devoted much attention to parenting. Studies addressing the issue of the relationship between parenting style and shyness have mainly focused on infancy and childhood. These surveys have shown that parents of shy children tend to be protective of, and intrusive toward, them. ${ }^{36,37}$

Parents of shy children may perceive their children's difficulties and might therefore believe that the best way to help them from potentially emotion-arousing situations is to control every aspect of their lives. ${ }^{4,5}$ Parents may organise their child's schedules, telling them how to do things or what to do, limiting their child's activities and behaviors, discouraging their efforts to explore unfamiliar situations autonomously, and taking over situations in which they expect that their children might feel anxious even when it isn't necessary. ${ }^{5}$

Nevertheless, such parenting practices may increase and reinforce shyness, maintaining or exacerbating children's difficulties. Since necessary opportunities to practice social skills and self-regulation are denied, these children may not learn to develop coping skills to deal with their social anxiety, and therefore they might not be able to overcome their fears. In fact, this overprotective, over-controlling parental style discourages risk taking and active exploration in unfamiliar situations. As such, it prevents the development of a belief system of self-efficacy and autonomy, and therefore perpetuates children's feelings of insecurity. ${ }^{38,39}$

However, certain parental behaviors may not only increase, but also decrease shy children's difficulties. In fact, some family environmental factors might moderate the relationship between shyness and psychological and social difficulties. For example, Coplan and colleagues have found that an overprotective parenting style was strongly associated with internalizing problems in shy children, such as anxiety, loneliness, and peer-rejection whereas supportive parenting was less associated with these psychological and social difficulties. ${ }^{6}$ Similarly, Rubin and colleagues have found that shy children whose mothers were intrusive and controlling toward them were more likely to demonstrate inhibited behavior with peers than those shy children whose mothers were less overprotective. ${ }^{40}$ In line with these results, other evidence has shown a strong association between maternal psychologically over-controlling behavior and higher degrees of social withdrawal and reticent behavior in shy children. ${ }^{41,42}$ Furthermore, other researchers have highlighted that overprotective maternal behaviour, as opposed to sensitive maternal behaviour, is a predictor of greater stability in inhibited child behavior over time. ${ }^{43}$

Although the relationship between shyness and parenting has been sufficiently explored in infancy and childhood, relatively little attention has been devoted to parenting style in shy adolescents. However, there is evidence that shy adolescents have a lower quality relationship with parents than do non-shy adolescents. ${ }^{9,44}$

Based on previous findings that have emphasised that parental behavior is still important during this developmental period, it seems relevant to also closely examine the child-parent relationship in shy adolescents. Hence, the aim of this study is to investigate shy adolescents' perceptions of their parental bond.

\section{The present study}

To date, few studies have investigated the relationship between shyness and the parental bond during adolescence. Moreover, very little is known about the extent to which this relationship may differ with regard to child gender and how it may change during the transition from early to late adolescence. 
Table I Means and standard deviations of parental bonding dimensions for early adolescents

\begin{tabular}{|c|c|c|c|c|c|c|c|c|c|c|c|c|}
\hline \multirow[b]{3}{*}{ Variables } & \multicolumn{6}{|l|}{ Shy } & \multicolumn{6}{|c|}{ Non-Shy } \\
\hline & \multicolumn{3}{|l|}{ Male } & \multicolumn{3}{|c|}{ Female } & \multicolumn{3}{|c|}{ Male } & \multicolumn{3}{|c|}{ Female } \\
\hline & $M$ & $S D$ & $\mathbf{n}$ & $M$ & $S D$ & $\mathbf{n}$ & $M$ & $S D$ & $\mathbf{n}$ & $M$ & $S D$ & $\mathbf{n}$ \\
\hline \multicolumn{13}{|l|}{ PBI-Father } \\
\hline Care & 35.13 & 6.40 & 73 & 35.20 & 6.18 & 61 & 38.24 & 4.49 & 52 & 37.21 & 7.25 & 41 \\
\hline Autonomy & 16.45 & 4.06 & 73 & 15.46 & 3.55 & 61 & 17.96 & 3.46 & 52 & 16.55 & 4.39 & 41 \\
\hline Overprotection & 7.41 & 2.90 & 73 & 7.62 & 2.94 & 61 & 6.26 & 1.97 & 52 & 7.05 & 3.00 & 41 \\
\hline \multicolumn{13}{|l|}{ PBI-mother } \\
\hline Care & 36.12 & 5.46 & 73 & 37.45 & 5.58 & 61 & 38.39 & 5.40 & 52 & 39.17 & 5.74 & 41 \\
\hline Autonomy & 16.53 & 3.26 & 73 & 15.17 & 3.13 & 61 & 17.19 & 3.38 & 52 & 16.80 & 4.58 & 41 \\
\hline Overprotection & 7.60 & 2.39 & 73 & 7.57 & 2.21 & 61 & 6.88 & 2.29 & 52 & 6.63 & 2.30 & 41 \\
\hline
\end{tabular}

Table 2 Means and standard deviations of parental bonding dimensions for late adolescents

\begin{tabular}{|c|c|c|c|c|c|c|c|c|c|c|c|c|}
\hline \multirow[b]{3}{*}{ Variables } & \multicolumn{6}{|l|}{ Shy } & \multicolumn{6}{|c|}{ Non-shy } \\
\hline & \multicolumn{3}{|l|}{ Males } & \multicolumn{3}{|c|}{ Females } & \multicolumn{3}{|c|}{ Males } & \multicolumn{3}{|c|}{ Females } \\
\hline & $M$ & $S D$ & $\mathbf{n}$ & $M$ & $S D$ & $\mathbf{n}$ & $M$ & $S D$ & $\mathbf{n}$ & $M$ & $S D$ & $\mathbf{n}$ \\
\hline \multicolumn{13}{|l|}{ PBI-Father } \\
\hline Care & 31.88 & 6.20 & 35 & 31.99 & 7.45 & 69 & 34.70 & 7.03 & 74 & 34.50 & 7.29 & 70 \\
\hline Autonomy & 19.28 & 2.66 & 35 & 17.73 & 3.43 & 69 & 19.7| & 3.45 & 74 & 18.14 & 3.33 & 70 \\
\hline Overprotection & 6.28 & 1.98 & 35 & 6.96 & $2.4 I$ & 69 & 5.49 & 1.69 & 74 & 6.60 & 2.30 & 70 \\
\hline \multicolumn{13}{|l|}{ PBI-Mother } \\
\hline Care & 34.26 & 4.83 & 35 & 35.99 & 6.43 & 69 & 36.15 & 5.89 & 74 & 36.86 & 6.67 & 70 \\
\hline Autonomy & 18.88 & 3.26 & 35 & 18.55 & 2.84 & 69 & 19.83 & 3.19 & 74 & 19.13 & 3.52 & 70 \\
\hline Overprotection & 7.48 & 2.57 & 35 & 7.39 & 2.49 & 69 & 6.46 & 2.78 & 74 & 6.93 & 2.44 & 70 \\
\hline
\end{tabular}

Table 3 Means, standard deviations and ANOVA F values by Group

\begin{tabular}{|c|c|c|c|c|c|c|c|}
\hline & Shy & & & Non- & & & \\
\hline Variables & $M$ & SD & $\mathbf{n}$ & $\mathbf{M}$ & SD & $\mathbf{n}$ & $\mathbf{F}$ \\
\hline \multicolumn{8}{|l|}{ PBI-father } \\
\hline Care & 33.76 & 6.79 & 238 & 35.85 & 6.83 & 237 & $16.98 * * *$ \\
\hline Autonomy & 16.98 & 3.77 & 238 & 18.32 & 3.74 & 237 & $6.40^{*}$ \\
\hline Overprotection & 7.17 & 2.68 & 238 & 6.25 & 2.26 & 237 & $9.98 * *$ \\
\hline \multicolumn{8}{|l|}{ PBI-mother } \\
\hline Care & 36.15 & 5.75 & 238 & 37.37 & 6.08 & 237 & $9.19 * *$ \\
\hline Autonomy & 17.11 & 3.42 & 238 & 18.52 & 3.85 & 237 & $8.78 * *$ \\
\hline Overprotection & 7.51 & 2.39 & 238 & 6.68 & 2.49 & 237 & $13.19 * * *$ \\
\hline
\end{tabular}

$*_{\mathrm{p}}<.05 ; *^{*} \mathrm{p}<.01 ; * *^{*} \mathrm{p}<.001$

Table 4 Means, standard deviations and ANOVA F values by Age

\begin{tabular}{|c|c|c|c|c|c|c|c|}
\hline \multirow[b]{2}{*}{ Variables } & \multicolumn{3}{|c|}{ Early-Adolescents } & \multicolumn{4}{|c|}{ Late-Adolescents } \\
\hline & $\mathbf{M}$ & SD & $\mathbf{n}$ & $\mathbf{M}$ & SD & $\mathbf{n}$ & $\mathbf{F}$ \\
\hline \multicolumn{8}{|l|}{ PBI-father } \\
\hline Care & 36.24 & 6.23 & 227 & 33.49 & 7.19 & 248 & $25.15^{* * * *}$ \\
\hline Autonomy & 16.55 & 3.94 & 227 & 18.66 & 3.4 & 248 & $38.43 * * *$ \\
\hline Overprotection & 7.14 & 2.78 & 227 & 6.32 & 2.2 & 248 & $9.79 * *$ \\
\hline \multicolumn{8}{|l|}{ PBI-mother } \\
\hline Care & 37.55 & 5.61 & 227 & 36.04 & 6.16 & 248 & $12.50 * * *$ \\
\hline Autonomy & 16.36 & 3.65 & 227 & 19.14 & 3.22 & 248 & $68.62 * * *$ \\
\hline Overprotection & 7.21 & 2.34 & 227 & 7 & 2.6 & 248 & 0.03 \\
\hline
\end{tabular}

$* p<.05 ; * * p<.01 ; * * p<.001$

Table 5 Means, standard deviations and ANOVA F values by Gender

\begin{tabular}{|c|c|c|c|c|c|c|c|}
\hline & Boys & & & Girls & & & \\
\hline Variables & $M$ & SD & $\mathbf{n}$ & $\mathbf{M}$ & SD & $\mathbf{n}$ & $\mathbf{F}$ \\
\hline \multicolumn{8}{|l|}{ PBI-father } \\
\hline Care & 35.2 & 6.47 & 234 & 34.42 & 7.25 & $24 I$ & 0.17 \\
\hline Autonomy & 18.24 & 3.79 & 234 & 17.08 & 3.75 & $24 I$ & $|6.4| * * *$ \\
\hline Overprotection & 6.38 & 2.34 & 234 & 7.04 & 2.65 & 241 & $8.84 * *$ \\
\hline \multicolumn{8}{|l|}{ PBI-mother } \\
\hline Care & 36.36 & 5.61 & 234 & 37.16 & 6.24 & $24 I$ & $4.20 *$ \\
\hline Autonomy & 18.07 & 3.6 & 234 & 17.56 & 3.79 & $24 I$ & $4.67 *$ \\
\hline Overprotection & 7.06 & 2.56 & 234 & 7.13 & 2.4 & 241 & 0.02 \\
\hline
\end{tabular}

$* p<.05 ; * * p<.01 ; * * * p<.001$

Citation: Lucia P, Franca T.Associations between shyness and maternal and paternal bonds across adolescence.J Psychol Clin Psychiatry. 20 I 7;7(5):I I-I2. DOI: 10.15406/jpcpy.20 I7.07.0045 I 
The purpose of this study was to examine relations between shyness and the perception of the parental bond, distinguishing maternal and paternal parenting. Indeed, some researchers have highlighted differences in adolescents' perceptions of their mothers and fathers, suggesting the need to distinguish these. Moreover, the parent-child relationship was examined separately for males and females, in order to detect possible differences relating to child gender. Finally, considering the transformations that occur in the parent-child relationship during adolescence, it may be reasonable to assume that parenting style may change, even in relation to shy adolescents, during the passage from early to late adolescence. So, in order to explore possible parenting style changes associated with child age, perceptions of parental relationships were separately measured for early adolescents and for late adolescents.

In light of the research on parenting in the area of shyness, the parental bond has been measured on three dimensions: care, encouragement towards autonomy, and overprotection. Based on the previously discussed literature, it was expected that shy subjects would perceive a poor quality parent relationship. Drawing upon previous research in this area, it was also hypothesized that shy adolescents would report their parents to be more overprotective and less encouraging of autonomy than their non-shy peers. Nevertheless, given the scarcity of data, no hypothesis was formulated about gender differences for shy adolescents' perceptions of the parental bond, or about changes occurring in the parent - shy-child relationship from early to late adolescence.

\section{Methods}

\section{Participants and procedure}

Research participants were recruited from six public schools in Florence, Italy. Participants were recruited while they were in class during school hours. Formal consent from parents and educational authorities was obtained prior to starting data collection.

Subjects completed a battery of questionnaires designed to gather information about personal and demographic data (i.e., age, gender, grade, and origin), and information about mothers' and fathers' school attendance and occupations. Moreover, the battery included a measure of the perceived parental bond from both mother and father and a measure of shyness.

A total of 595 students were recruited for the present study. These included a group of 11- to 13 - year-old early adolescents $(\mathrm{N}=278)$ who were attending one of three different secondary schools, and another group of 17 - to 19-year-old late adolescents $(\mathrm{N}=317)$ who were attending one of three high schools.

Ninety-nine participants came from the centre of Italy, particularly the area around Florence. Participants came from families of a middle to high socioeconomic background and more than $70 \%$ of the parents had a high school diploma or university degree.

After data collection, participants were selected based on a shyness scale score. Using the 40th and 60th percentile as cut-off points, subjects were identified as non-shy and shy, respectively. On the basis of these criteria, adolescents who weren't either shy nor non-shy were excluded from the analyses. The final total sample comprised 475 subjects. This included 227 early adolescents with a mean age of $12.40(\mathrm{SD}=.69)$, of whom 134 were classified to be shy ( 73 males and 61 females), and of whom 93 were categorised as non-shy (52 males and 41 females). The late-adolescent group was composed of 248 participants with a mean age of $17.71(\mathrm{SD}=.65)$, of whom 104 were categorised to be shy ( 35 males and 69 females) and 144 were classed as non-shy (74 males and 70 females).

\section{Measures}

\section{Shyness}

Shyness in participants was measured using the Revised Cheek and Buss Shyness Scale (Cheek, 1983). This scale is a unifactorial measure of shyness consisting of 13 items that measure discomfort and inhibition in social situations. Examples of items are: "I feel tense when I'm with people I don't know well" and "When in a group of people, I have trouble thinking of the right thing to say".

Items were measured on a 5-point scale ranging from 1 (very uncharacteristic) to 5 (extremely characteristic) with a maximum possible score of 65; the higher the score, the higher the shyness. Participants are requested to respond to each item according to the following instructions "Read each item carefully and decide to what extent it is characteristic of your feeling and behavior. Answer each question by choosing a number from the scale below".

This scale is a widely used measure of shyness and has shown good psychometric properties. Cheek (1983) reported a Coefficient alpha of .90 and other investigators have found Coefficient alphas of $.81,{ }^{46} .86 ; ;^{47,48} .88^{49}$ and $.90 .{ }^{50}$ Moreover, the scale has shown high testretest reliability. Some authors have reported a 45 -day retest reliability of $.88 .^{45,50}$

In this study, the Italian version of $R C B S^{51}$ was used. The results of the Italian adaptation have confirmed a unidimensional factorial structure. Confirmatory factor analytic procedures were used to assess the adequacy of the model, and the fit index indicated an adequate fit to the data $(\mathrm{CFI}=.91$; SRMR $=.06)$. Moreover, the internal reliability of the scale in this sample was .86 .

\section{Parental bonding}

Parental bonding was assessed via subjects' responses to the Parental Bonding Instrument by Parker et al. ${ }^{20}$ The Parental Bonding Instrument is a 25 -item, self-report questionnaire designed to measure an individual's perceptions of his or her parents' parenting style. There are two parallel versions, one for each parent, and each assesses two dimensions, parental care (12 items, for example "Appeared to understand my problems and worries") and parental overprotection (13 items, for example "Tended to baby me").

Participants were requested to respond to each item on a 4-point scale ranging from 0 (Very like) to 3 (Very unlike). The PBI subscales were scored separately. The "care" subscale has a maximum possible score of 36 , and the "overprotection" subscale has a maximum possible score of 39. The higher the score, the higher the parental care and overprotection. Respondents were asked to read each item and to assess their parent's behaviors and attitudes, answering each question by placing a cross in the most appropriate box next to each question.

The PBI scale has good internal consistency. For example, some authors found a Coefficient alpha of .92 and .87 for the paternal care and overprotection subscale, respectively; and of .94 and .88 for the maternal care and overprotection subscales, respectively. ${ }^{52}$ Rigby and colleagues found a-values of .86 and .86 for the mother care and overprotection subscale, and of .87 and .84 for the father care and overprotection subscale. ${ }^{24}$ Moreover, the Parental Bonding Instrument has demonstrated acceptable reliability over time with a Pearson correlation coefficient of .76 for the care subscale and of .63 for the overprotection subscale over a three-week period..$^{20}$ In a

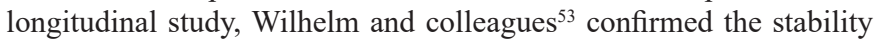
of the scale over a 20-year period. Retest coefficients varied from .64 to .83 for maternal care, and from .74 to .82 for paternal care; from 
.67 to .77 for maternal overprotection, and from .59 to .78 for paternal overprotection.

In this study, the Italian version of the Parental Bonding Instrument devised by Bonaiuto and colleagues ${ }^{35}$ was used. This version consists of 21 items. Four items were eliminated because their load factor was lower than .40 or loaded significantly on multiple factors (item 9, "Try to control everything I do"; item 16, "Make me feel I'm not want"; item 19, "Try to make me feel dependent on her/him"; and item 23, "Is overprotective of me"). Analyses conducted by Bonaiuto et al. have highlighted a three factor model, showing the same structure both for the mother and for the father, which accounts for a total of $47.2 \%$ of variance for the mother scale, and $50.9 \%$ for the father scale. The first factor that was extracted was "care and affectionate bond". It represents $24.8 \%$ of the overall variance for the mother scale and $28 \%$ of the overall variance for the father scale and it consists of 11 items. The second factor that was extracted was "encouragement towards autonomy and independence". It accounted for a further $13.6 \%$ of variance for the mother scale and $14.5 \%$ for the father scale, and it consists of 6 items. The last factor was "overprotection" which explained $8.9 \%$ of the variance for the mother scale and $8.4 \%$ of the variance for the father scale, and it consists of 4 items. In the Italian version, answers to items range on a 4-point scale from $1=\mathrm{I}$ don't agree at all, to $4=$ I fully agree. So, the care subscale has a maximum possible score of 44; the encouragement towards autonomy subscale has a maximum possible score of 24 ; and the highest possible score for the overprotection subscale is 14 .

\section{Results}

\section{Descriptive analysis}

The means and standard deviations of the three dimensions of the Parental Bonding Instrument for both the mother and father, namely "care", "autonomy and independence", and "overprotection", for early and late adolescent groups are presented in Table $1 \&$ Table 2, respectively.

\section{Parental bonding as a function of Shyness, Age, and Gender}

A multivariate analysis of variance (MANOVA) was conducted to assess the differences between groups in the perception of the parental relationship. A follow-up univariate ANOVA was conducted when the MANOVA results were significant. The independent variables were Group (shy and non-shy), Age (early adolescents and late adolescents), and Gender (males and females); and the dependent variables were the six parental bonding subscales, three for the mother scale and three for the father scale.

The overall MANOVA test revealed a significant difference between groups with respect to the dependent variables, Wilk's lambda $F(6,462)=13326.14, p<.001, \eta^{2}=.99$. In particular, there was a significant main effect for both Group, $F(6,462)=$ $4.81, p<.001, \eta^{2}=.06$; Age, $F(6,462)=25.47, p<.001, \eta^{2}=.25$; and Gender, $F(6,462)=5.10, p<.001, \eta^{2}=.06$. In contrast, there was no significant interaction effect for Group x Age, $F(6,462)=$ $.40, n s$, Group x Gender, $F(6,462)=.40, n s$, and Group x Age $\mathrm{x}$ Gender $F(12,924)=.58, n s$.

\section{Shyness and parental bonding}

Subsequent univariate analyses revealed that shyness was a significant factor for every parental bonding dimension, both in maternal and paternal scales. The means and results of the univariate $F$ tests can be seen in Table 3 . In particular, adolescents in the shy group perceived less care than did their non-shy peers, both from their fathers, $F(1,467)=16.98, p<.001, \eta^{2}=.04$ and from their mothers, $F(1,467)=9.18, p=.003, \eta^{2}=.02$. Shy adolescents also reported lower encouragement towards autonomy and independence than did non-shy youth, from both their fathers, $F(1,467)=6.40, p=$ $.012, \eta^{2}=.01$ and their mothers, $F(1,467),=8.78, p=.003, \eta^{2}=$. 02 . Furthermore, shy participants were more likely to perceive higher overprotection, from their fathers, $F(1,467)=9.98, p=.002, \eta^{2}=.02$, and from their mothers, $F(1,467)=13.19, p<.001, \eta^{2}=.03$, than did those in the non-shy group.

\section{Age and parental bonding}

Follow-up univariate analyses revealed that age was significant for all dependent variables, except maternal overprotection (Table 4). Results indicated that early-adolescents perceived higher care than did late-adolescents from their fathers, $F(1,467)=25.15, p<.001$, $\eta^{2}=.05$ and mothers, $F(1,467)=12.50, p<.001, \eta^{2}=.03$. Older adolescents reported greater encouragement towards autonomy and independence both from their fathers, $F(1,467)=38.43, p<.001$, $\eta^{2}=.08$, and from their mothers, $F(1,467)=68.62, p<.001, \eta^{2}=$ .13. Finally, younger adolescents perceived greater overprotection only from their fathers, $F(1,467)=9.79, p=.002, \eta^{2}=.02$, while no significant differences between early- and late-adolescents on perceived maternal overprotection, $F(1,467)=.03$, $n s$ emerged.

\section{Gender and parental bonding}

Significant between-subjects effects indicated that child gender was influential in all the dimensions of parental bonding, except paternal care and maternal overprotection (Table 5). Girls perceived higher levels of maternal care than did boys, $F(1,467)=4.20, p=$ $.041, \eta^{2}=.01$; while no differences emerged between boys and girls in relation to perceived levels of paternal care, $F(1,467)=$ .17 , ns. However, boys perceived higher levels of encouragement towards autonomy and independence than did girls, both from their fathers, $F(1,467)=16.41, p<.001, \eta^{2}=.03$ and mothers, $F(1,467)$ $=4.67, p=.031, \eta^{2}=.01$. Furthermore, girls reported their fathers as being more overprotective than did boys, $F(1,467)=8.84, p=.003$, $\eta^{2}=.02$, but no differences emerged between the two genders for maternal overprotection, $F(1,467)=.02, n s$.

\section{Discussion}

The goal of this study was to examine the relationship between shyness and specific parenting practices (i.e., care, encouragement towards autonomy and independence, and overprotection) during adolescence. This relationship was investigated by examining the differences between shy and non-shy young people's perceptions of their parents' behaviors. Moreover, such perceptions were examined in relation to gender and age. Overall, the results of the present study have shown significant differences on participants' perceptions of parental bonding.

In particular these findings support the results of previous investigations on the influential role of parents in the development of shyness in their children. Youths who reported experiencing high levels of shyness perceived their parents differently than youths who reported experiencing low levels of shyness.

As predicted, results showed that the shy group of adolescents perceived their parents to be less warm and close, and less encouraging of their independence than did the non-shy group. Shy adolescents also reported greater levels of overprotection from both parents than did 
non-shy adolescents. These results are consistent with the findings of previous studies on parenting style in shyness during childhood, ${ }^{9,41,42}$ and during adolescence. ${ }^{9,44}$ Specifically, researchers have found that parents who have shy children tend to be intrusive and overprotective. Moreover, these parents may respond to shyness in their children with behaviors that tend to restrict their children's freedom and autonomy in an attempt to help them. ${ }^{5}$

The present findings highlight the fact that parental use of psychological control and intrusiveness in the lives of shy children tends to continue even after childhood. Moreover, these results can extend knowledge about the role of the parenting bond in shyness, especially during a stage that has received little attention in the shyness literature. In fact, as previously discussed, most of the investigations on parenting style in children's shyness have focused on infancy and childhood, and the adolescent period has been largely neglected. However, our results suggest that during this developmental period, shy adolescents continue to perceive their parents as more protective and intrusive than of non-shy children do. Shy adolescents also perceived their both mother and father to be neglectful and aloof, while non-shy adolescents perceive their parental relationships as characterized by higher levels of closeness and emotional support.

Moreover, the results of the current study show no significant differences between shy boys' and girls' perceptions of parental care. From this point of view, our results are not consistent with the ones of previous study carried out on infancy. For example, Engfer ${ }^{54}$ has found that shyness in girls during infancy and childhood was associated with positive aspects of the child-parent relationship, while the reverse was the case for shyness in boys. On adolescence this difference seems not to be present. This result, however, needs further investigation.

In relation to age, results indicated no differences between shy early and late adolescents in their perceptions of the parental bond. Both younger and older shy adolescents' perceptions of care, encouragement towards independence, and overprotection from their parents weren't significantly different in both age groups. Hence, possible changes in perceptions of parental behaviors during adolescence do not seem to depend on whether a subject is shy or not.

There were several limitations in the present work. First, the cross-sectional study design limits the possibility to understand the development trajectories of the child-parent relationship from early to late adolescence. Other more rigorous designs, like longitudinal projects, would be needed to better understand this relation. Moreover, all data were collected via self-report measures. Although these instruments represent an important source of information, the use of multiple methods to integrate the subjective point of view with other source of external information, for example maternal and paternal evaluation, would be appropriate.

Despite these limitations, the present study adds to our understanding of the links between parental bond and shyness during adolescence, highlighting important differences in parenting style between shy and non-shy adolescents. Such knowledge will provide useful information for clinicians that are interested in developing interventions for shy individuals.

\section{Acknowledgments}

None.

\section{Conflicts of interest}

Author declares there are no conflicts of interest.

\section{Funding}

None.

\section{References}

1. Dawson G, Ashman SB. On the origins of a vulnerability to depression: The influence of the early social environment on the development of psychobiological systems related to risk for affective disorder. In: The Effects of Adversity on Neurobehavioral Development: Minnesota Symposia on Child Psychology, Mahwah, Lawrence Erlbaum and Associates, NJ, USA. 2000. p.245-278.

2. Van Wel F, Linssen H, Abma R. The parental bond and the well-being of adolescents and young adults. Journal of Youth and Adolescence. 2000;29(3):307-318.

3. Alloy LB, Abramson LY, Smith JM, et al. Role of parenting and maltreatment histories in unipolar and bipolar mood disorders: Mediation by cognitive vulnerability to depression. Clin Child Fam Psychol Rev. 2006;9(1):23-64.

4. Burgess $\mathrm{KB}$, Rubin $\mathrm{KH}$, Cheah $\mathrm{C}$, et al. Behavioral Inhibition, social withdrawal, and parenting. In: Crozier \& Alden (Eds.), International handbook of social anxiety: Concepts, research, and interventions relating to the self and shyness, Chichester, Wiley, UK. 2001. p.137-158.

5. Rubin KH, Burgess KB, Coplan RJ. Social withdrawal and shyness. In: Smith \& Hart (Eds.), Blackwell handbook of Childhood Social Development, Blackwell Publishing, Malden, MA, US. 2002. p.330-352.

6. Coplan RJ, Arbeau KA, Armer M. Don't fret, be supportive! Maternal characteristics linking child shyness to psychosocial and school adjustment in kindergarten. Journal of Abnormal Child Psychology. 2008;36:359-371.

7. Ciairano S, Bonino S, Jackson S, et al. Stile educativo genitoriale e benessere psicosociale in adolescenza. Una ricerca in due nazioni europee. Età Evolutiva. 2001;69:61-71.

8. Han PG. Wu YP, Gao FQ. The development of teacher reported scale for preschool children's shyness. Psychological Research. 2014;7(3):58-62.

9. Nelson LJ, Padilla-Walker LM, Badger S, et al. Associations between shyness and internalizing behaviors, externalizing behaviors, and relationships during emerging adulthood. Journal of Youth and Adolescence. 2008;37(5):605-615.

10. Kimberley AA, Coplan RJ, Weeks M. Shyness, teacher-child relationships, and socioemotional adjustment in grade one. International Journal of Behavioral Development. 2010;34(3):259-269.

11. Nelson LJ, Rubin KH, Fox NA. Social withdrawal, observed peer acceptance, and the development of self-perceptions in children ages 4 to 7 years. Early Childhood Research Quarterly. 2005;20:185-200.

12. Crozier WR. Shyness and social relationships: Continuity and change. In: Crozier (Ed.), Shyness: Development, Consolidation, and Change, Routledge, New York, USA. 2000. p.1-21.

13. Caprara GV, Gerbino M, Barbaranelli C. Correlati e determinanti personali della timidezza e della solitudine nell'adolescenza. Psicologia Clinica dello Sviluppo. 2005. p. 85-115.

14. Chavira DA, Stein MB, Malcarne VL. Scrutinizing the relationship between shyness and social phobia. J Anxiety Disord. 2002;16(6):585-598.

15. Goodwin RD, Fergusson DM, Horwood LJ. Early anxious/withdrawn behaviours predict later internalising disorders. J Child Psychol Psychiatry. 2004;45(4):874-883.

16. Heiser NA, Turner SM, Beidel DC. Shyness: relationship to social phobia and other psychiatric disorders. Behav Res Ther. 2003;41(2):209-221. 
17. Asendorpf JB. Shyness and adaptation to the social world of university In: Crozier (Ed.), Shyness: Development, Consolidation, and Change, Routledge, New York, USA. 2000. p.103-120.

18. Ponti L, Tani F. Shyness and psychologial adjustment: the moderating role of friendship relationships. Journal of Psychopathology. $2015 ; 21: 36-52$

19. Coplan RJ, Prakash K, O’Neil K, et al. Do you "want" to play? Distinguishing between conflicted-shyness and social disinterest in early childhood. Dev Psychol. 2004;40(2):244-258.

20. Parker G, Tupling H, Brown LB. A parental bonding instrument. British Journal of Medical Psychology. 1979;52(1):1-10.

21. Stattin H, Kerr M. Parental monitoring: a reinterpretation. Child Dev. 2000;71(4):1072-1085.

22. Martin G, Bergen HA, Roeger L, et al. Depression in young adolescents: Investigations using 2 and 3 factor versions of the parental bonding instrument. J Nerv Ment Dis. 2004;192(10):650-657.

23. Enns MW, Cox BJ, Clara I. Parental bonding and adult psychopathology: results from the US National Comorbility Survey. Psychol Med. 2002;32(6):997-1008.

24. Rigby K, Slee PT, Martin G. Implications of inadequate parental bonding and peer victimization for adolescent mental health. $J$ Adolesc. 2007;30(5):801-812.

25. Pierro A, Bonaiuto M, Ercolani AP, et al. Rete sociale dell'adolescente e immagine di sé: un modello di equazioni strutturali per variabili latenti». Giornale Italiano di Psicologia, USA. 1996. p.275-291.

26. Greenberger E, Chen C, Tally SR, et al. Family, peer, and individual correlates of depressive symptomatology among US and Chinese adolescents. J Consult Clin Psychol. 2000;68(2):209-219.

27. Cui M, Conger D, Bryant CM, et al. Parental behavior and the quality of adolescent friendships: A social-contextual perspective. Journal of Marriage and Family. 2002; 64(3):676-689.

28. Arim RG, Shapka JD. The impact of pubertal timing and parental control on adolescent problem behaviors. Journal of Youth and Adolescence. 2008;37(4):445-455.

29. Pettit GS, Laird RD, Dodge KA, et al. Antecedents and behaviorproblem outcomes of parental monitoring and psychological control in early adolescence. Child Dev. 2001;72(2):583-598

30. Noller P, Callan V. The adolescent in the family. Routledge, London, UK. 1991.

31. Cicognani E. La percezione degli stili educativi genitoriali negli. Bollettino di Psicologia Applicata. 2002;236:19-31.

32. Furman W, Buhrmester D. Age and sex differences in perceptions of networks of personal relationships. Child Dev. 1992;63(1):103-115.

33. McGue M, Elkins I, Walden B, et al. Perception of the parentadolescent relationship: A longitudinal investigation. Dev Psychol. 2005;41(6):971-984.

34. Van Wel F, ter Bogt T, Raaijmakers Q. Changes in the parental bond and the well-being of adolescents and young adults. Adolescence. 2002;37(146):317-333.

35. Bonaiuto M, Perucchini P, Pierro A. L'adolescente e i membri significativi della sua rete sociale. Adolescent and significant members of his social network. Età Evolutiva. 1997;57:40-56.

36. Chen YM, Gao FQ, \& Han L. Shyness: A review of evidence from behavioral genetics. Advances in Psychological Science. 2013;21(7):1220-1228
37. Nelson LJ, Hart CH, Wu B, et al. Relations between Chinese mothers' parenting practices and social withdrawal in early childhood. International Journal of Behavioral Development. 2006;30(3):261-271.

38. Rubin KH, Burgess K. Parents of aggressive and withdrawn children. In: M. Bornstein (Ed.), Handbook of Parenting, (2nd edn), Hillsdale, Lawrence Erlbaum Associates, NJ, USA. 2002. p.383-418.

39. Rubin KH, Burgess KB, Hastings PD. Stability and social-behavioral consequences of toddlers' inhibited temperament and parenting behaviors. Child Dev. 2002;73(2):483-495.

40. Rubin KH, Hastings PD, Stewart SL, et al. The consistency and concomitants of inhibition: Some of the children, all of the time. Chil Dev. 1997;68(3):467-483.

41. Hane AA, Cheah $\mathrm{C}$, Rubin $\mathrm{KH}$, et al. The role of maternal behavior in the relation between shyness and social reticence in early childhood and social withdrawal in middle childhood. Social Development. 2008;17(4):795-811.

42. Rubin KH, Cheah CS, Fox NA. Emotion regulating, parenting and display of social reticence in preschoolers. Early Education and Development. 2001;12(1):97-115.

43. Early D, Rimm-Kaufman SE, Cox M, et al. Maternal sensitivity and wariness in the transition to kindergarten. Parenting: Science \& Practice. 2002;2(4):355-377.

44. Tani F, Ponti L, Smorti M. Shyness and psychological adjustment during adolescence: the moderating role of parenting style. The Open Psychology Journal . 2014;10(7):33-44.

45. Cheek JM. The Revised Cheek and Buss Shyness Scale (RCBS). Unpublished manuscript. Wellesley College, Wellesley, MA. USA. 1983.

46. Paulsen E, Bru E, Murberg T. Passive students in junior high school: The associations with shyness, perceived competence and social support. Social Psychology of Education. 2006;9(1):67-81.

47. Amico KR, Bruch MA, Haase RF, et al. Trait shyness, actual-ought self-discrepancy and discomfort in social interaction. Personality and Individual Differences. 2004;36:1597-1610.

48. Hopko DR, Stowell J, Jones WH, et al. Psychometric Properties of the Revised Cheek and Buss Shyness Scale. J Pers Assess. 2005;84(2):185-192.

49. Miller JL, Schmidt LA, Vaillancourt T. Shyness, sociability, and eating problems in a non-clinical sample of female undergraduates. Eat Behav. 2008;9(3):352-359.

50. Phillips SD, Bruch MA. Shyness and dysfunction in career development. Journal of Counseling Psychology. 1988;35:159-165.

51. Ponti L, Tani F. Uno strumento per rilevare la timidezza nella preadolescenza: l'adattamento italiano della Revised Cheek and Buss Shyness Scale. Infanzia e Adolescenza, Italy. 2009. p.165-174.

52. Safford SM, Alloy LB, Pieracci A. A comparison of two measures of parental behavior. Journal of Child and Family Studies. 2007; 16:375-384.

53. Wilhelm K, Niven H, Parker G, et al. The stability of the Parental Bonding Instrument over a 20-year period. Psychol Med. 2005;35(3):387-393.

54. Engfer A. Antecedents and consequences of shyness in boys and girls: A 6-years longitudinal study. In: Rubin \& Asendorfp (Eds.), Socia Withdrawal, Inhibition, and Shyness, Erlbaum, Hillsdale, USA. 1993. p. 49-80. 